\title{
Ag-Coated Cu/Polylactic Acid Composite Filament for Lithium and Sodium-Ion Battery Current Collector Three-Dimensional Printing via Thermoplastic Material Extrusion
}

\author{
Alexis Maurel ${ }^{1,2,3 *}$, Hyeonseok Kim ${ }^{1,3}$, Roberto Russo ${ }^{1,3,4}$, Sylvie Grugeon ${ }^{1,3}$, \\ Michel Armand ${ }^{1}$, Stephane Panier ${ }^{2}$ and Loic Dupont ${ }^{1,3,5 *}$ \\ ${ }^{1}$ Laboratoire de Réactivité et de Chimie des Solides, Université de Picardie Jules Verne, Amiens, France, ${ }^{2}$ Laboratoire des \\ Technologies Innovantes, Université de Picardie Jules Verne, Amiens, France, ${ }^{3}$ Réseau français sur le stockage électrochimique \\ de l'énergie, Amiens, France, ${ }^{4}$ Department Electric Equipment Laboratory (LME), EDF R\&D, Morêt-Sur-Loing, France, \\ ${ }^{5}$ Plateforme de Microscopie Électronique (PME) de l'Université de Picardie Jules Verne, Amiens, France
}

OPEN ACCESS

Edited by:

Soorathep Kheawhom, Chulalongkorn University, Thailand

Reviewed by: Ahmad Azmin Mohamad, University of Science Malaysia, Malaysia

Lyn Marie De Juan-Corpuz, University of Santo Tomas, Philippines

*Correspondence: Loic Dupont loic.dupont@u-picardie.fr Alexis Maurel alexis.maurel@u-picardie

Specialty section: This article was submitted to Electrochemical Energy Conversion and Storage,

a section of the journal Frontiers in Energy Research

Received: 08 January 2021 Accepted: 08 February 2021 Published: 15 April 2021

Citation:

Maurel A, Kim H, Russo R, Grugeon S, Armand $M$, Panier $S$ and Dupont $L$ (2021) Ag-Coated Cu/Polylactic Acid Composite Filament for Lithium and Sodium-Ion Battery Current Collector Three-Dimensional Printing via Thermoplastic Material Extrusion. Front. Energy Res. 9:651041. doi: 10.3389/fenrg.2021.651041
This article focuses on the development of polylactic acid- (PLA-) based thermoplastic composite filament for its use, once 3D printed via thermoplastic material extrusion (TME), as current collector at the negative electrode side of a lithium-ion battery or sodium-ion battery. High electronic conductivity is achieved through the introduction of $\mathrm{Ag}$-coated $\mathrm{Cu}$ charges, while appropriate mechanical performance to allow printability was maintained through the incorporation of poly(ethylene glycol) dimethyl ether average $M_{n} \sim 500$ (PEGDME500) as a plasticizer into the PLA polymer matrix. Herein, thermal, electrical, morphological, electrochemical, and printability characteristics are discussed thoroughly. While Ag-Li alloy formation is reported at $0.1 \mathrm{~V}$ upon cycling, its use with active materials such as $\mathrm{Li}_{4} \mathrm{Ti}_{5} \mathrm{O}_{12}(\mathrm{LTO})$ or $\mathrm{Li}_{2}$-terephthalate $\left(\mathrm{Li}_{2} \mathrm{TP}\right)$ operating at a plateau at higher potential is demonstrated. Furthermore, its ability to be used with negative electrode active material of sodium-ion battery technology in a wide potential window is demonstrated.

Keywords: lithium-ion battery, current collector, material extrusion, 3D-printing, composites

\section{INTRODUCTION}

Over the last few years, numerous studies dedicated to the lithium-ion battery (LIB) 3D printing have been published in the literature (Pang et al., 2019; Browne et al., 2020; Cheng et al., 2020; Costa et al., 2020; Egorov et al., 2020; Gulzar et al., 2020; Lyu et al., 2020; Maurel et al., 2020c; Yang et al., 2020; Yang and Fan, 2020; Zeng et al., 2020; Zhang et al., 2020). This trend can be simply justified by the new design freedom offered by the innovative additive manufacturing (AM) processes. Indeed, thanks to such cutting-edge technology, it is now possible to imagine the development of LIB threedimensional (3D) architectures reported to increase the electroactive surface area greatly, allowing the $\mathrm{Li}^{+}$diffusion towards two or three dimensions and thus improving the final electrochemical performance of the battery in terms of specific capacity and power (Trembacki et al., 2019; Maurel et al., 2020b); on the other hand, conventional 2D LIB architectures of the positive electrode, separators, negative electrode, and current collector are stacked or rolled (parallel plates configuration), previously reported to allow only $\mathrm{Li}^{+}$diffusion in 1D. While 3D LIB structures, originally proposed by Long et al. (Long et al., 2004; Long et al., 2020), were extensively developed 


\section{Thermoplastic Material Extrusion (TME)}

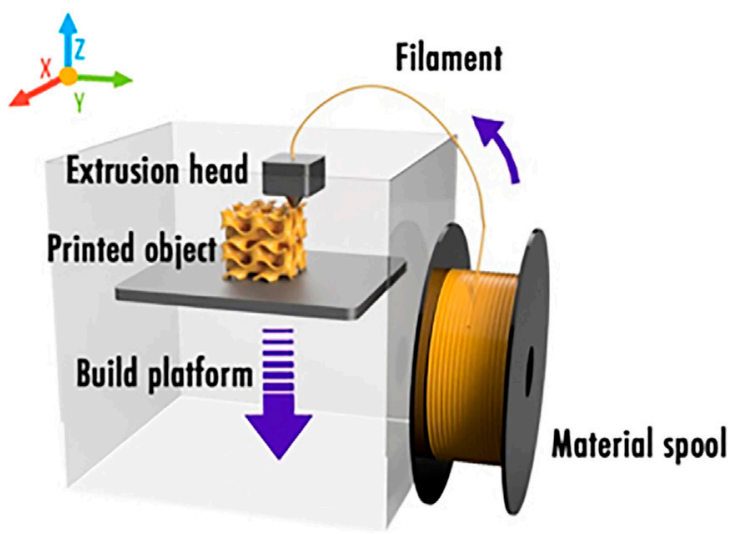

FIGURE 1 | Thermoplastic material extrusion 3D printing scheme.

independently through traditional techniques such as electrodeposition, the assembly of both electrodes manually was reported to be particularly complex due to the irregular electrode surfaces causing short circuits (Taberna et al., 2006). As an innovative alternative and to prevent this last issue, AM appears as a unique route to obtain such complex interlaced electrode architectures. Additionally, such a technique also opens the way towards topological optimization by directly introducing the energy storage device within the whole available free space of the object.

Among the various offered 3D printing processes, thermoplastic material extrusion (TME), also commonly called fused deposition modeling (FDM), was investigated recently due to its undeniable advantage allowing the elaboration of a complete LIB in one-single step without requiring any extra postprocesses compared to other AM techniques such as direct ink writing (DIW) or stereolithography apparatus (SLA) that generally require freeze-drying, debinding, and/or sintering (Sun et al., 2013; Fu et al., 2016; Cohen et al., 2018). A classical TME printer (Figure 1) is usually fed with a $1.75 \mathrm{~mm}$ diameter thermoplastic filament that is heated few degrees above its melting temperature to be selectively deposited through a nozzle. Being computer-controlled, the latter is indeed moved so as to build the final $3 \mathrm{D}$ object layer after layer. Commercial desktop TME 3D printers have a layer thickness resolution of about $150 \mu \mathrm{m}$ for the first layer and down to $50 \mu \mathrm{m}$ for the subsequent layers.

Starting from 2017, various groups initiated the development of bespoke composite 3D printable filaments, specifically developed to print components of a classical LIB: positive electrodes (PLA/ $\mathrm{LiFePO}_{4}$ (Ragones et al., 2018; Maurel et al., 2019), PP/LiFePO 4 (Maurel et al., 2020), PLA/LMO (Reyes et al., 2018)), negative electrodes (PLA/graphite (Maurel et al., 2018; Maurel et al., 2019), PLA/LTO (Ragones et al., 2018; Reyes et al., 2018)), separator (PLA/SiO 2 (Maurel et al., 2019)) and solid polymer electrolyte (PEO/LiTFSI (Maurel et al., 2020a), PLA/
PEO/LiTFSI (Ragones et al., 2019)). In 2018, an important milestone was reached in the field as our group (Maurel et al., 2018) reporting for the first time that the introduction of a thoroughly chosen plasticizer helps to increase the number of charges within the composite filament considerably. Indeed, highly loaded PLA/graphite (Maurel et al., 2018) and PLA/ $\mathrm{LiFePO}_{4}$ (Maurel et al., 2019) filaments with up to $62 \mathrm{wt} \%$ of active material were, respectively, formulated as negative and positive electrodes. This was made possible through the introduction of poly(ethylene glycol) dimethyl ether average $\mathrm{Mn} \sim 500$ (PEGDME500) as a plasticizer to enhance its flexibility. After optimization by introducing a conductive additive within the composite, a negative electrode (Maurel et al., 2018) (tested in a half-cell configuration using $1 \mathrm{M} \mathrm{LiPF}_{6}$ in ethylene carbonate and diethyl carbonate as liquid electrolyte) depicted a reversible capacity of $200 \mathrm{mAhg}^{-1}$ of active material (99 $\mathrm{mAhg}^{-1}$ of the total composite or also to $154.6 \mathrm{mAh} \mathrm{cm}^{-3}$ ) at current density of $18.6 \mathrm{mAg}^{-1}(\mathrm{C} / 20)$ after six cycles and $140 \mathrm{mAhg}^{-1}$ of active material $\left(69 \mathrm{mAhg}^{-1}\right.$ of the total composite or also $108.2 \mathrm{mAhcm}^{-3}$ ) at current density of $37.3 \mathrm{mAg}^{-1}(\mathrm{C} / 10)$. Likewise, the optimized 3D printed positive electrode developed by our group (Maurel et al., 2019) exhibited reversible capacity values of about $87 \mathrm{mAhg}^{-1}$ of active material $\left(43 \mathrm{mAhg}^{-1}\right.$ of the total composite or also to $77 \mathrm{mAhcm}^{-3}$ ) at current density of $8.5 \mathrm{mAg}^{-1}(\mathrm{C} / 20), 45 \mathrm{mAhg}^{-1}$ of active material $\left(22 \mathrm{mAhg}^{-1}\right.$ of the total composite or also to $\left.40 \mathrm{mAhcm}^{-3}\right)$ at a current density of $17 \mathrm{mAg}^{-1}(\mathrm{C} / 10)$, and $22 \mathrm{mAhg}^{-1}$ of active material (11mAh $\mathrm{g}^{-1}$ of the total composite or also to $\left.20 \mathrm{mAhcm}^{-3}\right)$ at a current density of $34 \mathrm{mAg}^{-1}(\mathrm{C} / 5)$.

While the last efforts (Maurel et al., 2020c) were exclusively focused on the development of $3 \mathrm{D}$ printable composite thermoplastic filaments for the positive electrode, negative electrode, and separator and solid polymer electrolyte, it is now required to focus on the last piece of the LIB puzzle: the development of a 3D printable composite current collector filament, specially designed for LIB application. Being the direct connection between the electrode and the external circuit, current collectors must exhibit electronical conductivity as high as possible and inertness towards the electrode materials and the electrolyte. Hence, metal foils are usually employed in commercial LIB. Thus, the metal selection for each current collector should be chosen in good agreement with their own electrochemical stability window. Copper foil is generally employed as current collector at the negative electrode as it appears to be electrochemically stable down to $0 \mathrm{~V}$ vs. $\mathrm{Li}^{2} / \mathrm{Li}^{+}$ (Myung et al., 2011). On the other hand, aluminum foil current collector (cheaper and lighter) is used at the positive electrode as it is stable at higher potential due to the $\mathrm{AlF}_{3}$ passivating layer created thanks to the presence of $\mathrm{LiPF}_{6}$ salt (Forestier et al., 2016), thus blocking subsequent aluminum oxidation. $\mathrm{Al}$ is not used at the negative electrode as an $\mathrm{Li}-\mathrm{Al}$ alloying process starts when potential is close to $\sim 0.3 \mathrm{~V}$ vs. $\mathrm{Li} / \mathrm{Li}^{+}$(Myung et al., 2011). Practically, extended corrosion of current collectors under cycling can lead to an increase of the cell overall resistance causing capacity fading. In extreme cases, it could even induce short circuit, affecting the device's safety. Finally, it is important to mention that metallic foil current collectors, usually serving as 
support for the coated electrodes, can generate some adhesion issues due to their smooth surface. Indeed, metallic foils can unfortunately cause the active material particles detachment reported to be particularly problematic for flexible electrode manufacturing. Hence, carbon-based materials or conducting polymers may be potential candidates for flexible current collectors (Singh et al., 2012).

Destined here as a preliminary work, the mission of this research was to study the possibility of introducing copper particles within a PLA polymer matrix to develop a current collector (negative electrode side) composite 3D printable filament for LIB or SIB applications. As depicted hereafter, film, filament, and $3 \mathrm{D}$ printed discs were characterized by means of differential scanning calorimetry (DSC), electrochemical impedance spectroscopy (EIS), galvanostatic cycling with potential limitation (GCPL) technique, and scanning electron microscopy (SEM). In order to improve the electronic conductivity, the introduction of a silver coating on top of the copper particles by electroless deposition and its impact on the final composite current collector were investigated. By means of electrochemical characterization, the lower limit of the working potential window of the optimized current collector composition was then studied. Subsequently, adequate electroactive materials were proposed.

\section{EXPERIMENTAL}

\section{Materials}

Polylactic acid (PLA 4032D) pellets were provided by NatureWorks, United States. Dichloromethane (DCM) solvent was supplied by VMR Chemicals, United States. Copper particles $(\mathrm{Cu})$ (particle size between 10 and $25 \mu \mathrm{m}$ ) purchased from Sigma Aldrich, Europe, were used as conductive material for the current collector of the LIB. Poly(ethylene glycol) dimethyl ether average $\mathrm{M}_{\mathrm{n}} \sim 500$ (PEGDME500), $\mathrm{H}_{2} \mathrm{SO}_{4}$ sulfuric acid (97\% concentration), $\mathrm{AgNO}_{3}$ silver nitrate $\left(99.9 \%\right.$ concentration) $\left(\mathrm{NH}_{4}\right)_{2} \mathrm{CO}_{3}$ ammonium carbonate (99\% concentration), and $\mathrm{NH}_{4} \mathrm{OH}$ ammonium hydroxide (28\% concentration) were all purchased from Sigma Aldrich, Europe. Terephthalic acid (98\% concentration) powder was provided by Alfa Aesar, Thermo Fischer Scientific, United States. $\mathrm{LiOH} \cdot \mathrm{H}_{2} \mathrm{O}$ (98\%) powder was purchased from Sigma Aldrich, Europe. $\mathrm{Li}_{2}-$ terephthalate $\left(\mathrm{Li}_{2} \mathrm{TP}\right)$ was synthesized using the procedure reported by Armand et al. (Armand et al., 2009). $\mathrm{Li}_{4} \mathrm{Ti}_{5} \mathrm{O}_{12}$ (LTO) was supplied by MTI Corporation, United States. Carbon Black Timcal Super-P (SSA: $62 \mathrm{~m}^{2} \mathrm{~g}^{-1}$ ) was supplied by Sigma Aldrich, USA. Hard carbon (HC) powder $\left(2.8 \mathrm{~m}^{2} \mathrm{~g}^{-1}\right)$ was provided by GEM Holding Corporation, Japan.

\section{Deposition of an Ag Coating on Top of the Cu Powder}

Silver was coated on copper through the redox process in order to prevent the oxidation of the surface of copper and enhance the electronic conductivity. The first step consisted of introducing
$50 \mathrm{~g}$ of the copper powder in a sulfuric acid solution (sulfuric acid $20 \mathrm{ml}+$ diluted water $200 \mathrm{ml}$ ) for $2 \mathrm{~min}$ so as to remove oxide layers Eq. (1).

$$
\mathrm{CuO}(\mathrm{s})+\mathrm{H}_{2} \mathrm{SO}_{4}(\mathrm{aq}) \rightarrow \mathrm{CuSO}_{4}(\mathrm{aq})+\mathrm{H}_{2} 2 \mathrm{O}(\mathrm{s}) .
$$

According to Lee et al., $2.7 \mathrm{~nm}$ of oxide layer can be etched by diluted $\mathrm{H}_{2} \mathrm{SO}_{4}$ with a volume ratio of $\mathrm{H}_{2} \mathrm{SO}_{4}$ to water of 1:20 for $2 \mathrm{~min}$ (Lee et al., 2013). The resulting neat copper powder was then washed until the $\mathrm{pH}$ of copper reached the $\mathrm{pH}$ of DI water and finally introduced in $100 \mathrm{ml}$ of DI water. On the other hand, $7.85 \mathrm{~g}$ of silver nitrate, $100 \mathrm{~g}$ of ammonium carbonate, and aqueous ammonia were mixed together in $100 \mathrm{ml}$ of distilled water to create a silver complex solution. Lastly, the silver complex solution was gradually added to copper powder suspension over a period of $5 \mathrm{~min}$ at room temperature. The mixture of copper and silver complex solution was stirred further for an hour to create a silver shell on top of the copper powder. As reported in the literature (Hai et al., 2006), the activated copper on the surface of copper powder is displaced with silver ion according to the following Eq. (2):

$$
\mathrm{Cu}+2\left[\mathrm{Ag}\left(\mathrm{NH}_{3}\right)_{2}\right] \mathrm{NO}_{3} \rightarrow\left[\mathrm{Cu}\left(\mathrm{NH}_{3}\right)_{4}\right]\left(\mathrm{NO}_{3}\right)_{2}+2 \mathrm{Ag} .
$$

It is worth mentioning that the $\mathrm{pH}$ of the silver complex solution is reported to have a strong impact on the deposition rate of $\mathrm{Ag}$ onto $\mathrm{Cu}$, surface morphology, roughness, crystallinity, polarization, and impedance behavior. A mixture of aqueous ammonia and ammonium carbonate solution is used in this experiment $\left(\mathrm{NH}_{4}{ }^{+} / \mathrm{NH}_{3}, \mathrm{pKa}=9.2\right)$. Large amounts of the ammonia water and ammonium carbonate compound are required with regard to the amount of silver nitrate because ammonia also acts as a complexing agent. Furthermore, the ideal molar ratio of ammonium carbonate to ammonia solution is reported to be from 0.1 to 3 (Koto et al., 1987). If the molar ratio is out of range, it has a negative effect on the conductivity of the coating layer. In this experiment, a molar ratio of 7.8 : 7.2 (ammonium carbonate to ammonia) was employed.

\section{Film Formulation}

After complete dissolution of the polymer matrix in a solvent (DCM at ambient temperature for PLA) with a weight ratio polymer matrix/solvent 1:10, PEGDME500 plasticizer was introduced to the mixture (PLA: PEGDME500 wt\% 100:40). The resulting slurry was then mixed for $30 \mathrm{~min}$ prior to the introduction of the conductive $\mathrm{Cu}$-based powder (polymer matrix:Cu-based powder wt\% 10:90) and stirred magnetically for $1 \mathrm{~h}$. For each sample, the prepared slurries were deposited onto a glass substrate by tape casting. After drying under ambient environment for $2 \mathrm{~h}$, samples were further dried under vacuum for 24h; in the case of LTO, another drying step was added, $4 \mathrm{~h}$ under vacuum at $110^{\circ} \mathrm{C}$. The obtained free-standing 100 and 250 $\mu \mathrm{m}$-thick films then undergo further characterization experiments. Thicker film samples were employed for EIS measurements and for performing SEM imaging, while thinner films were characterized by DSC and through galvanostatic electrochemical tests. 


\section{Composite Filaments Formulation}

As depicted in our previous articles (Maurel et al., 2018; Maurel et al., 2019; Maurel et al., 2020a; Maurel et al., 2020b), a Filabot Original extruder provided by Filabot Triex LLC, United States, was fed consistently with $3 \times 3 \mathrm{~mm}$ composite film pieces to get standard $1.75 \mathrm{~mm}$ diameter $3 \mathrm{D}$ printing filaments. Extruder temperature was set about $20^{\circ} \mathrm{C}$ higher than the melting temperature of the composite film deduced from DSC. The resulting filament was subsequently rolled around a spool by means of a Filabot spooler (Filabot Triex LLC, United States). The extruder was methodically cleaned with pure PLA polymer matrix before extrusion of each sample. Current collector filaments were then kept in a suitable storage environment with low humidity and at low temperature to avoid the evaporation of plasticizer.

\section{Thermoplastic Material Extrusion Printing}

Current collector 3D discs $(11 \mathrm{~mm}$ diameter, $200 \mu \mathrm{m}$ or $1 \mathrm{~mm}$ thick) were designed by means of Autodesk Fusion 360 software, after which they were divided into $100 \mu \mathrm{m}$ thick 2D slices using PrusaSlicer software and printed by a Prusa MK3S 3D printer (Prusa Research, Czech Republic) to perform further EIS and cyclic voltammetry. Nozzle ordinary input and output diameters of 1.75 and $0.4 \mathrm{~mm}$, respectively, were employed. The highest resolution in the $Z$ direction is $200 \mu \mathrm{m}$ for the first layer and $50 \mu \mathrm{m}$ for the following. The nozzle temperature was set $20^{\circ} \mathrm{C}$ higher than the melting temperature of the composite film and the fan settings were set to $100 \%$. Bed temperature was set to $60^{\circ} \mathrm{C}$ to favor the adherence of the first printed layer. Prior to printing each sample, the nozzle was purged thoroughly by printing a $2 \mathrm{~cm}^{3}$ purge cube with the corresponding filament.

\section{Differential Scanning Calorimetry (DSC)}

Thermal characterization of films, filaments, and 3D printed discs was carried out by means of a DSC204F1 supplied by NETZSCHGerätebau GmbH, Germany. All prepared samples were characterized between -60 and $300 \mathrm{C}$ at a heating rate of $10 \mathrm{Cmin}^{-1}$ under argon atmosphere $\left(50 \mathrm{mlmin}^{-1}\right)$, using about $10 \mathrm{mg}$ of sample of each composition. Heat flow data from the first heating operation were recorded.

\section{Electron Microscopy}

By means of a FEI Quanta200F (Thermo Fisher Scientific, United States) SEM in high vacuum mode, the material dispersion and sample homogeneity were investigated. The secondary and backscattered images were recorded with a $5 \mathrm{kV}$ acceleration voltage. Energy-dispersive X-ray spectroscopy (EDS) elementary maps $(\mathrm{Cu}, \mathrm{Ag}, \mathrm{O})$ were recorded at $20 \mathrm{kV}$.

\section{Electrical Conductivity Characterization}

EIS tests were achieved using an MTZ-35 frequency response analyzer and an intermediate temperature system (ITS) supplied by BioLogic, France. The exact same procedure as the one reported in our previous work was followed (Maurel et al., 2018). Inductive phenomena from cables were compensated by performing calibration of the empty ITS with the same cables. Current collector films (transversal section, $250 \mu \mathrm{m}$ thick) and filament (longitudinal section, $2 \mathrm{~mm}$ long) were subsequently introduced into a controlled environment sample holder $(\mathrm{CESH})$ to perform $\mathrm{AC}$ impedance measurement under air at temperatures varying from 20 to $60^{\circ} \mathrm{C}$ (upon heating in steps of $5 \mathrm{C})$. An excitation voltage of $10 \mathrm{mV}$, a frequency range of $20-0.05 \mathrm{~Hz}$ (20 points per decade and 10 measurements per point), and a soak time of $15 \mathrm{~min}$ were applied here. Electronic conductivities and activation energy were deduced from the Nyquist and phase Bode plots of the complex impedance. Conductivities were calculated from Eq. (3).

$$
\sigma=\frac{1}{R} \times \frac{d}{A}
$$

where $\mathrm{d}$ is the pellet thickness, $\mathrm{A}$ is the pellet surface area, and $\mathrm{R}$ is the respective resistances determined from the Nyquist and Bode plots.

\section{Electrochemical Characterization}

Inside an argon-filled glovebox $\left(\mathrm{H}_{2} \mathrm{O}<0.1 \mathrm{ppm}, \mathrm{O}_{2}<0.1 \mathrm{ppm}\right)$, Swagelok-type cells were assembled. Metallic lithium and metallic sodium were used as counter/reference electrodes for half-cells, while Ag-coated $\mathrm{Cu}$-based samples were used as working electrodes. The fiberglass separator was provided by Whatman, GE Healthcare, United States. A $150 \mu \mathrm{l}$ of $1 \mathrm{M} \mathrm{LiPF}_{6}$ in ethylene carbonate and diethyl carbonate (EC:DEC 1:1 weight ratio) and $150 \mu \mathrm{l}$ of $1 \mathrm{M} \mathrm{NaPF} 6$ in ethylene carbonate and dimethyl carbonate (EC:DMC 1:1 weight ratio) were used as an electrolyte, respectively, and supplied by Merck KGaA, Germany. Cells were galvanostatically discharged (lithiation or sodiation) and charged (delithiation or desodiation) at a current of $50 \mu \mathrm{A}$, between 0.005 and $1.5 \mathrm{~V}$ (vs. $\mathrm{Li} / \mathrm{Li}^{+}$and vs. $\mathrm{Na} / \mathrm{Na}^{+}$) by means of a BCS-805 (BioLogic, France) to see if an alloy with Li or $\mathrm{Na}$ metal was created. On the other hand, electrochemical tests using LTO film (LTO, carbon black, PVdF-HFP in a weight ratio of $65: 14: 21)$ deposited on top of the produced Ag-coated $\mathrm{Cu}$ current collector were performed at a current of $45.5 \mu \mathrm{A}(\mathrm{C} / 20)$, $91 \mu \mathrm{A}(\mathrm{C} / 10)$ and $182 \mu \mathrm{A}(\mathrm{C} / 5)$, between 1.3 and $2.0 \mathrm{~V}$ (vs. $\mathrm{Li} / \mathrm{Li}^{+}$). Tests using $\mathrm{Li}_{2} \mathrm{TP}$ powder $\left(\mathrm{Li}_{2} \mathrm{TP}\right.$, carbon black, in a weight ratio of 70:30 thoroughly mixed in a mortar) deposited on top of the Ag-coated $\mathrm{Cu}$ produced current collector were performed at a current of $1.161 \mathrm{~mA}(\mathrm{C} / 5)$ and $2.903 \mathrm{~mA}(\mathrm{C} / 2)$, between 0.5 and $2.0 \mathrm{~V}$ (vs. $\left.\mathrm{Li} / \mathrm{Li}^{+}\right)$. Finally, tests using $\mathrm{HC}$ powder $\left(2.8 \mathrm{~m}^{2} / \mathrm{g}\right.$ ) deposited on top of the produced $\mathrm{Ag}$-coated $\mathrm{Cu}$ current collector were performed at a current of $50 \mu \mathrm{A}$, between 0.005 and $1.5 \mathrm{~V}$ (vs. $\mathrm{Na} / \mathrm{Na}^{+}$). Electrochemical tests were performed at $20^{\circ} \mathrm{C}$.

\section{RESULTS AND DISCUSSIONS}

\section{Neat Cu-Based Current Collector Film}

The first part of this study was dedicated to the formulation of a neat Cu-based current collector composed of PLA/Cu/ PEGDME500, wt $\% 9.6 / 86.5 / 3.8$ or vol\% $36.6 / 46.0 / 17.3$. This particular composition was chosen as it corresponds to the maximum amount of charges (here, $\mathrm{Cu}$ ) that can be added within a polymer matrix without compromising the 


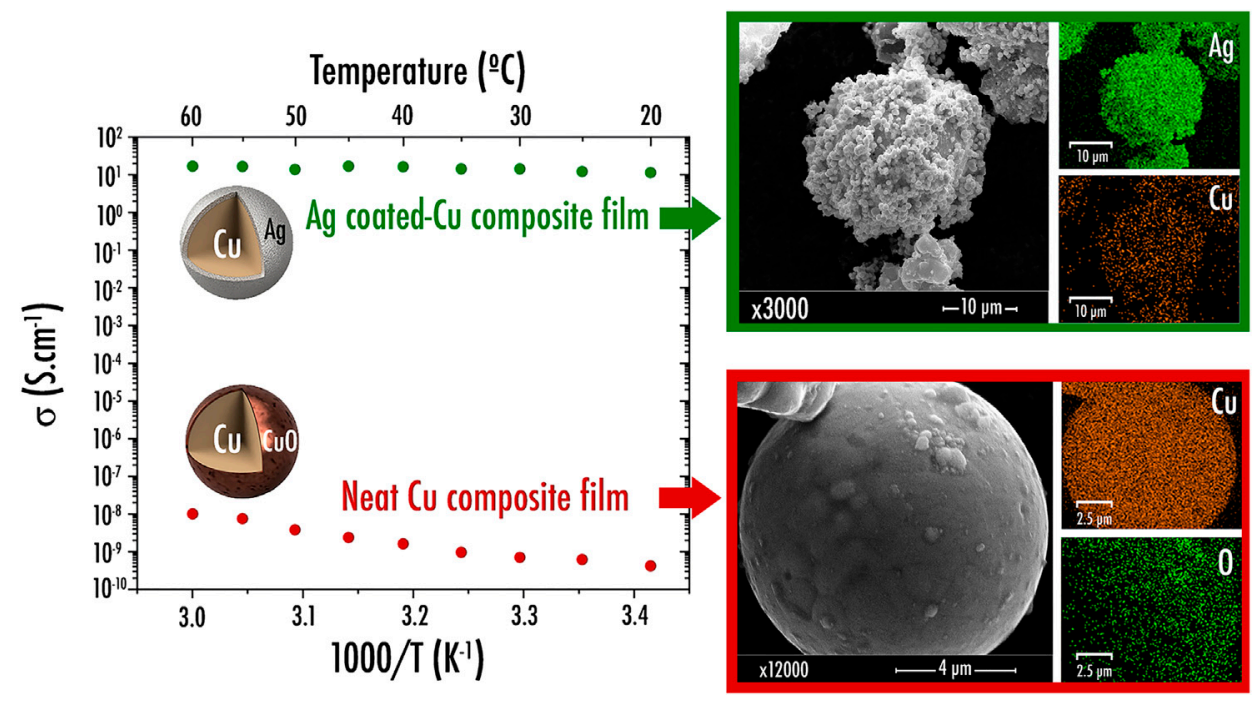

FIGURE 2 | Arrhenius plots of the electrical conductivity for film current collector samples containing neat copper and silver-coated copper and their respective SEM image and element distribution map (Ag, Cu, and O) obtained by Energy Dispersive X-ray Spectroscopy (EDS).

printability of the resulting composite filament as depicted in our previous study (maximum limit of 50 vol\%) (Maurel, 2020). For this particular sample composition, the achieved Nyquist and Bode curves were in accordance with an electronic conductor classical behavior as the Nyquist plot portrayed only Z' real part, while $|Z|$ magnitude remained steady for all frequencies. While an increase of temperature causing conductivity values to decrease is usually exhibited by pure metals, here, due to its composite nature, the sample rather exhibits a semiconductortype behavior as the electrical conductivity is rising with temperature, as shown in Figure 2. Here, an activation energy value of $0.678 \mathrm{meV}$ was estimated for the composite sample containing neat $\mathrm{Cu}$. Furthermore, it appears that this film sample is very poorly conductive $\left(4.2 \times 10^{-10} \mathrm{Scm}^{-1}\right.$ at $20^{\circ} \mathrm{C}$ and about $1.0 \times 10^{-8} \mathrm{Scm}^{-1}$ at $\left.60^{\circ} \mathrm{C}\right)$. Hence, its use as current collector in a LIB or SIB is highly compromised. This trend clearly corroborates the SEM/EDS observations that highlighted the presence of a $\mathrm{CuO}$ insulating layer on the surface of the $\mathrm{Cu}$ particles (Figure 2). Such a layer has been generated spontaneously upon storage. Since such a $\mathrm{CuO}$ passivation layer is known to be highly insulating and, as a metal oxide, is electrochemically reactive towards lithium through the socalled conversion reaction (Grugeon et al., 2001), a protocol was established to dissolve it and subsequently depose a homogeneous $\mathrm{Ag}$ layer on the surface of the $\mathrm{Cu}$ particles. This was done with a view to prevent surface copper from oxidation and enhance the electronic conductivity.

Following the deposition of $\mathrm{Ag}$ on the surface of the $\mathrm{Cu}$ particles, the resulting powder was thus characterized via SEM/EDS. Noticeably, as depicted in Figure 2, it appears that the aforementioned protocol worked properly as Ag was clearly identified on the $\mathrm{Cu}$ particles surface. Deposit morphology is particularly interesting as Ag was precipitated as beads $(\sim 1 \mu \mathrm{m}$ diameter). Nonetheless, it is worth mentioning that further thorough TEM experiments are still required in the future to precisely determine the thickness of the Ag layer.

Similar to what was achieved previously for the sample containing neat $\mathrm{Cu}$, the conductivity of the composite film PLA/Ag-coated Cu/PEGDME500 (wt\% 9.6/86.5/3.8) was investigated through EIS. As displayed in Figure 2, the sample containing Ag-coated $\mathrm{Cu}$ powder was shown to exhibit a drastically higher conductivity reaching $11.3 \mathrm{Scm}^{-1}$ at $20^{\circ} \mathrm{C}$ (multiplied by $2.8 \times 10^{10}$ times in comparison with composite film sample containing neat $\mathrm{Cu}$ ), thus paving the way towards the preparation of a highly conductive current collector filament. Here again, the sample exhibits a semiconductor-type behavior with an activation energy value of $0.071 \mathrm{meV}$.

\section{Ag-Coated Cu-Based Current Collector 3D Printable Filament}

The elaboration of a composite filament, here comprising PLA/ Ag-coated Cu/PEGDME500 (wt\% 9.6/86.5/3.8), specially designed to be used as a current collector within a LIB or SIB was initiated. Analogous to what was done in our previous studies regarding electrodes (Maurel et al., 2018; Maurel et al., 2019; Maurel et al., 2020b), separator (Maurel et al., 2019) or solid polymer electrolyte (Maurel et al., 2020a), the sample was first of all characterized via DSC. From this experiment, as shown in Figure 3A, serving here as a reference, neat PLA displays an endothermal peak related to the melting temperature (Tm) at 146C and a sharp peak corresponding to the glass transition $(\mathrm{Tg})$ appearing at $63 \mathrm{C}$. Instead, through the introduction of such a high number of charges (Ag-coated $\mathrm{Cu}$ particles) within the polymer matrix, the endothermal peak corresponding to the melting temperature was slightly shifted to a lower temperature (emerging at 142C), while $\mathrm{Tg}$ was no longer distinctly visible. PEGDME500 melting temperature appeared 

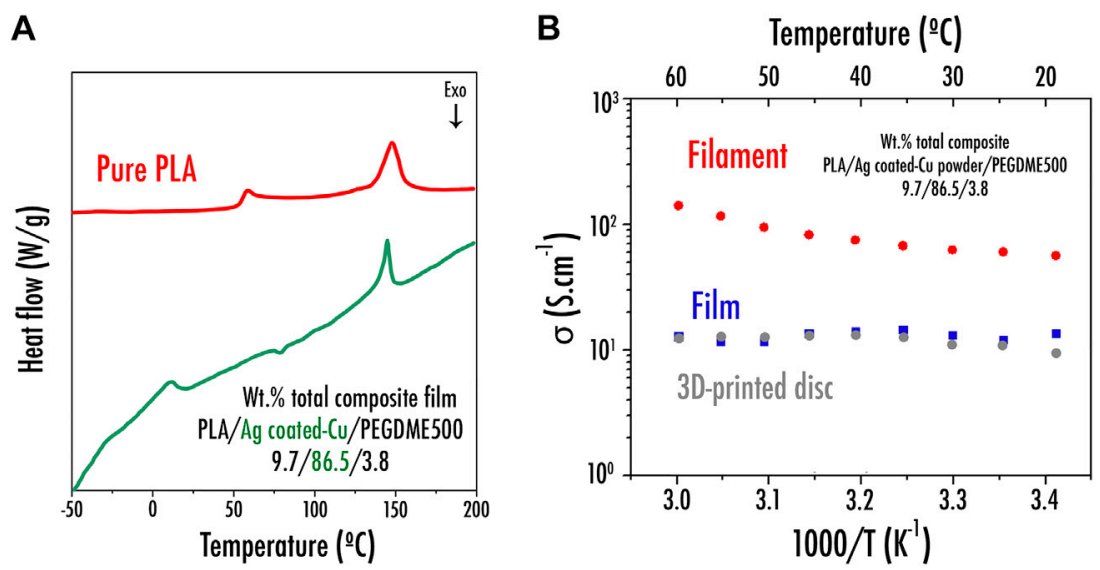

FIGURE 3 | (A) DSC curve for neat PLA and the prepared PLA/Ag-coated Cu powder/PEGDME500 film; (B) Arrhenius plots of the electrical conductivity for wt\% PLA/Ag-coated Cu powder/PEGDME500 9.7/86.5/3.8 film, filament, and 3D printed disc current collector samples.

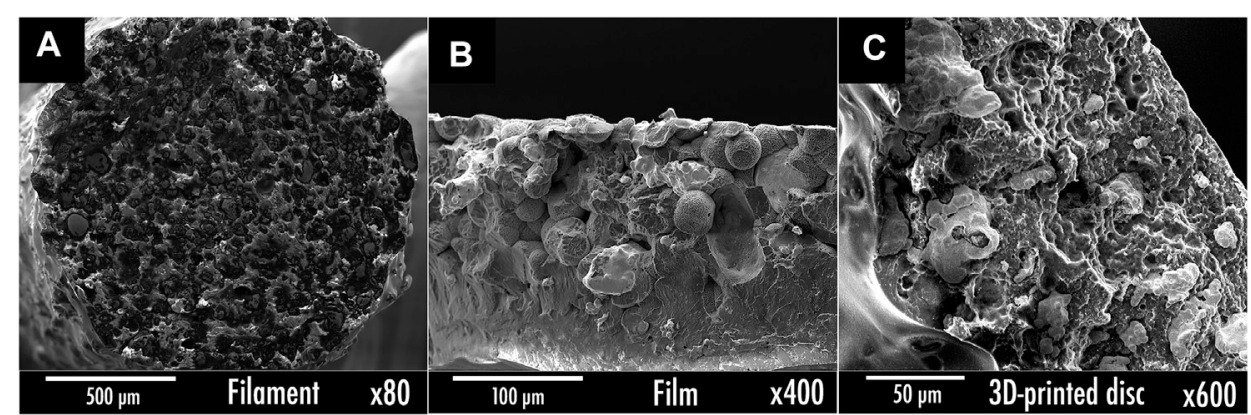

FIGURE 4 | Cross-sectional SEM images of the wt\% PLA/Ag-coated Cu powder/PEGDME500 9.7/86.5/3.8 (A) filament; (B) film; (C) 3D printed disc.

at about $5^{\circ} \mathrm{C}$, while the crystallization temperature of the Agcoated $\mathrm{Cu}$ composite film emerged at $75^{\circ} \mathrm{C}$. From these values, it was decided to produce the corresponding filament by fixing the extruder temperature at a slightly higher temperature of $162^{\circ} \mathrm{C}$. Based on the work reported by Ragones et al. (Ragones et al., 2019), the percentage of crystallinity of the polymer matrix was calculated using Eq. (4):

$$
X_{c}=\frac{\Delta H_{m}-\Delta H_{c}}{w . \Delta H_{100}} .100,
$$

where $\Delta H_{m}$ is the value of melting enthalpy, $\Delta H_{c}$ is the crystallization enthalpy, $\Delta H_{100}$ is the enthalpy of the completely crystalline PLA serving here as reference (93.6)/g for PLA (Li et al., 2015; Ragones et al., 2019)), and $w$ is the weight fraction of polymer in the sample. While from the DSC experiments, it was demonstrated that a neat PLA pellet depicts a crystallinity of $42 \%$, here, a crystallinity of about $47 \%$ (not considering the plasticizer evaporation) was calculated from the Ag-coated $\mathrm{Cu}$-based film. This value is in good agreement with what was observed previously for PLA/graphite (42\% of crystallinity) and $\mathrm{PLA} / \mathrm{LiFePO}_{4}$ (45\%), with a similar vol\% loading of charges (active material/conductive additive) (Maurel, 2020).
Figure 3B exhibits the EIS results of both PLA/Ag-coated Cu/PEGDME500 (wt\% 9.6/86.5/3.8) film and filament. The transversal section was characterized by EIS for the film sample, whereas the longitudinal section was rather studied for the filament. The conductivity of filament is improved by 9 times compared with what was obtained for the film. This behavior can be explained by the more homogeneous distribution of the Ag-coated $\mathrm{Cu}$ powder within the filament microstructure, as corroborated by SEM. Indeed, as displayed in Figure $\mathbf{4 B}$, during the film formulation, Ag-coated $\mathrm{Cu}$ charges tend to sediment by gravity upon solvent evaporation due to their relatively high density, thus forming a composition gradient that ultimately results in a nonhomogenous sample. On the other hand, via extrusion, the resulting sample (Figure 4A) clearly seems homogenous as charges are uniformly dispersed within the PLA matrix.

The electrical resistivity of the Ag-coated Cu/PLA/ PEGDME500 filament was then compared with commercially available conductive filaments. Filaments length of $10 \mathrm{~cm}$ were cut and resistance was measured with a multimeter from both ends. Following the protocol established by the company Multi3D LLC 


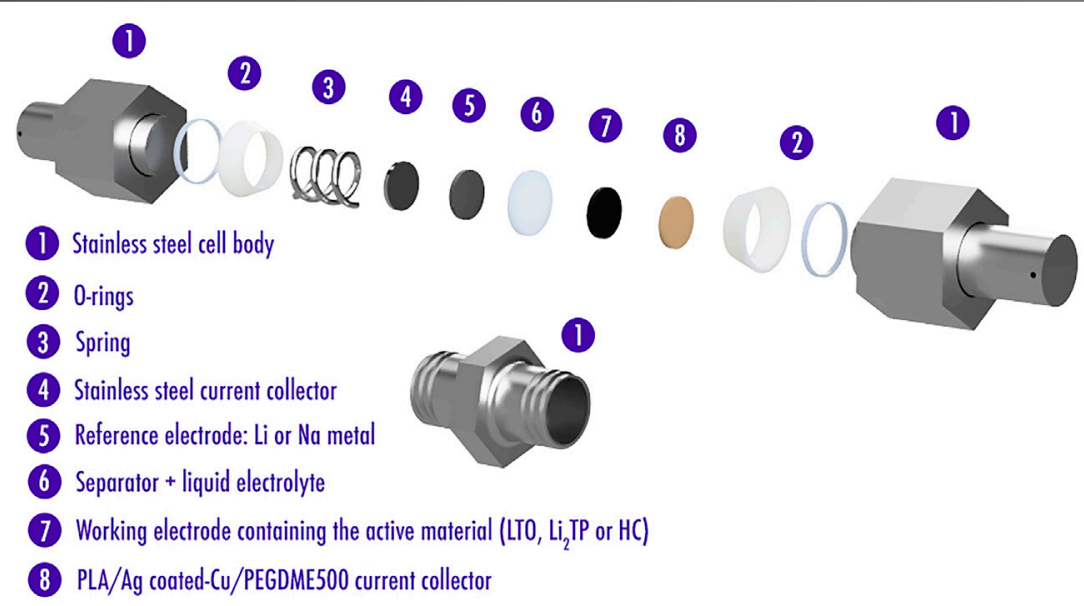

FIGURE 5 | Swagelok-type cells assembly for further electrochemical experiments.

on their website (https://www.multi3dllc.com), silver paste was applied to the ends of the filament before performing the measurement in order to reduce the contact resistance between the probes and the filament. Subsequently, the resistivity values were calculated according to the following Eq. (5):

$$
\rho=\frac{R \times \pi r^{2}}{L},
$$

where $\rho$ is the resistivity of the filament in $\Omega \mathrm{cm}$, $R$ is the resistance in $\Omega, L$ corresponds to the filament length in $\mathrm{cm}$, and $\mathrm{r}$ is the radius of the filament in $\mathrm{cm}$.

After calculations, it appears that the Ag-coated $\mathrm{Cu}$-based filament produced in this work depicts a resistivity of $0.112 \Omega \mathrm{cm}$. It is thus much more conductive than commercial filaments produced by Proto-Pasta

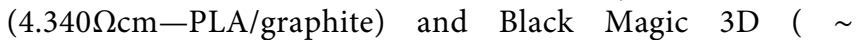
$0.6 \Omega \mathrm{cm}-\mathrm{PLA} / \mathrm{graphene)}$ but less conductive than the commercial Electrifi filament (Multi3D LLC) (resistivity value of about $0.006 \Omega \mathrm{cm}$ ). Hence, the electrical performance could still be optimized through the addition of conductive additives (CSP, CNF, or CNT) or other aspect ratios of $\mathrm{Ag}$-coated $\mathrm{Cu}$ additive. On the other hand, from the mechanical standpoint, it is worth mentioning that even if the TME printability of the Ag-coated $\mathrm{Cu}$ filament was demonstrated, its printability is still complex due to the introduction of such a high fraction of conductive charges compared with the less conductive commercial Proto-Pasta and Black Magic filaments. Indeed, here, due to the significant number of Ag-coated $\mathrm{Cu}$ particles, an accumulation of particles occasionally occurs within the nozzle head through printing, thus blocking the $0.4 \mathrm{~mm}$ nozzle outlet. In order to find the best compromise between electrical performance and printability, future studies may be focused on the development of $3 \mathrm{D}$ printing filament via coextrusion. Therefore, charges could be concentrated in the central part of the filament while a thin coating of pure polymer matrix would wrap it. Such coextruded filament would undoubtedly be much easier to print as it would considerably prevent nozzle clogging issues.

\section{Ag-Coated Cu-Based Current Collector 3D Printed Disc}

The previously prepared Ag-coated $\mathrm{Cu}$-based filament was subsequently introduced as a material source to feed the FDM $3 \mathrm{D}$ printer. The resulting 3D printed current collector discs were finally obtained and their electrical capability to be used as current collector for the negative electrode was examined (Figure 5). The first step consisted in testing the 3D-printed Ag-coated Cu/PLA/PEGDME500 disc vs. lithium metal directly. From this experiment, as depicted in Figure 6A representing the first discharge profile, an endless plateau corresponding to the alloying process occurring between $\mathrm{Ag}$ and Li metal was observed at $0.08 \mathrm{~V}$. Consequently, the use of such Ag-coated $\mathrm{Cu}$-based current collector is unfortunately strictly limited to higher potentials, thus limiting its application to only certain types of active material such as LTO or organic materials such as $\mathrm{Li}_{2} \mathrm{TP}$, depicting a plateau at 1.5 and $0.7 \mathrm{~V}$, respectively. After depositing LTO film (Figure 6B) or $\mathrm{Li}_{2} \mathrm{TP}$ powder (Figure 6C) on top of the Ag-coated Cu/PLA/PEGDME500 current collector disc, capacity retentions of both samples were recorded. At the tested current densities (C/20, C/10, and C/5), LTO film (Figure 6B) depicts capacity retention very close to the theoretical capacity of the active material $\left(175 \mathrm{mAhg}^{-1}\right)$. This trend here confirms the ability of the Ag-coated Cu/PLA/PEGDME500 sample to be used as current collector. On the other hand, a cell containing $\mathrm{Li}_{2} \mathrm{TP}$ powder as active material was also tested. As exhibited in Figure 6C, when deposited on top of the Ag-coated Cu/PLA/ PEGDME500 3D printed disc, the organic material depicts capacity retention very close to the one achieved without the current collector. It is worth mentioning that, here, the relatively poor electrochemical properties (in comparison with what was achieved in the literature (Armand et al., 2009) using similar active material (up to $300 \mathrm{mAhg}^{-1}$ )) are only related to the active 


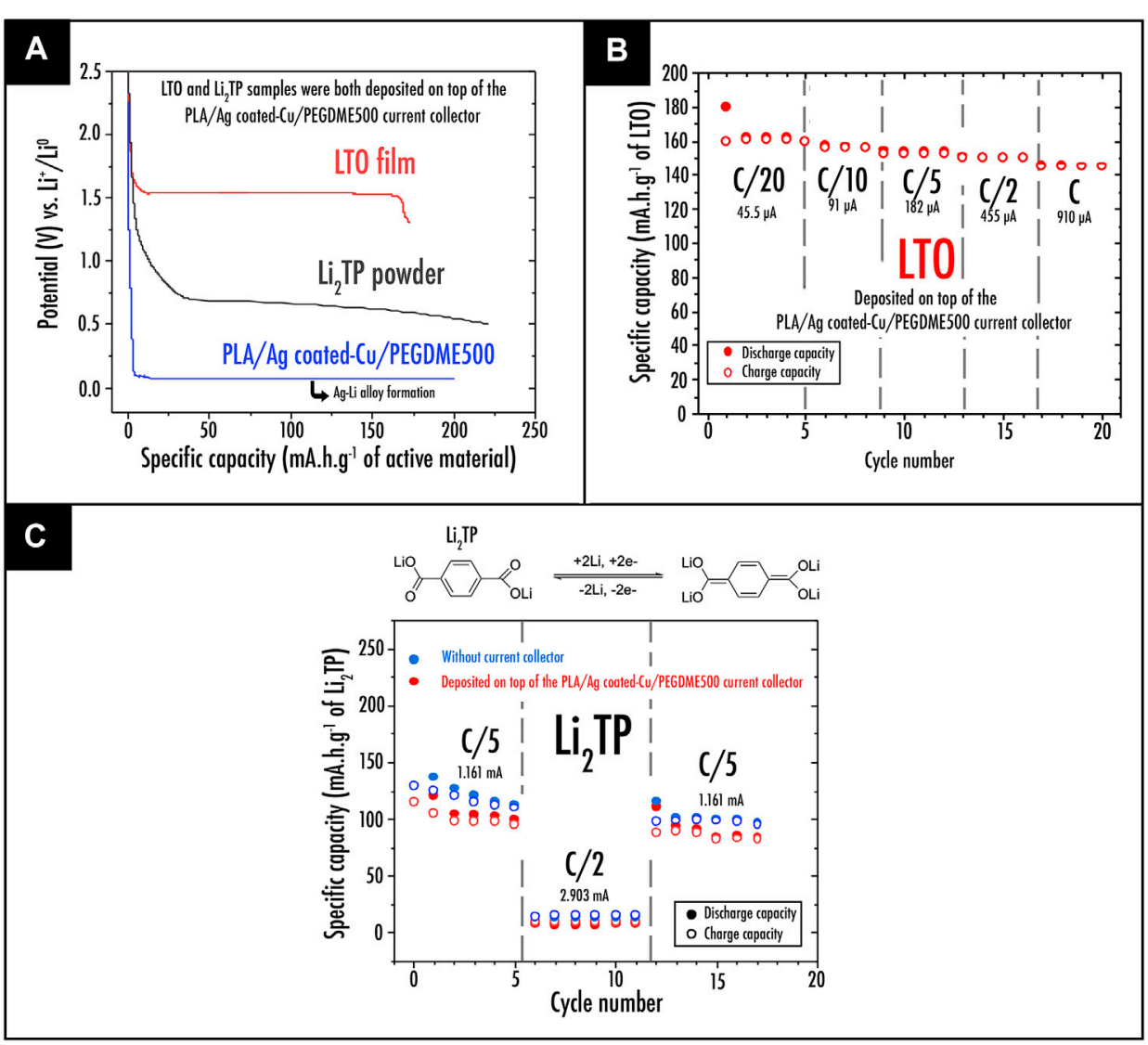

FIGURE 6 | (A) First discharge profile; (B) capacity retention plots at different C-rate for the LTO film (LTO, carbon black, and PVdF-HFP in a weight ratio of 65:14: 21) deposited on top of the 3D printed PLA/Ag-coated Cu/PEGDME500 current collector; (C) capacity retention plots at different C-rate for the Li 2 TP powder preparation ( $\mathrm{Li}_{2} \mathrm{TP}$ and carbon black, in a weight ratio of 70:30 thoroughly mixed in a mortar) deposited on top of the 3D printed PLA/Ag-coated Cu/PEGDME500 current collector.
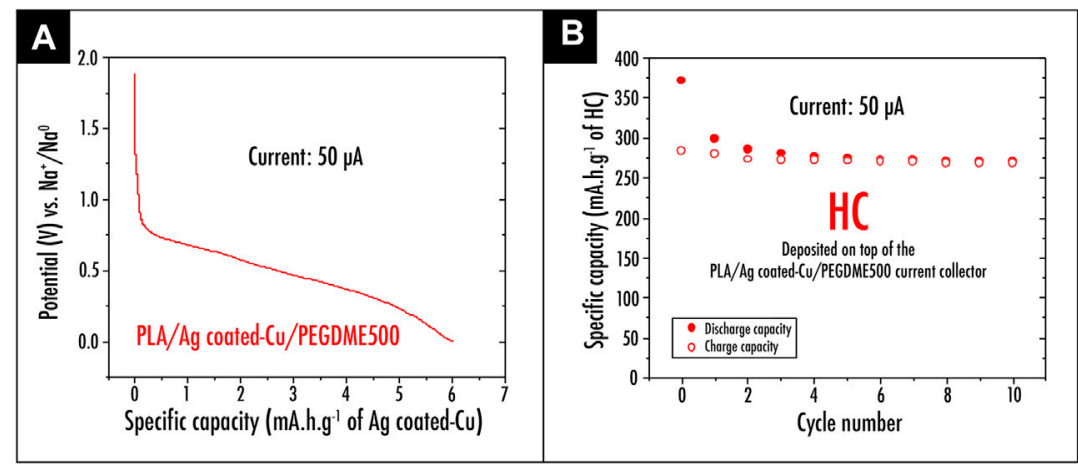

FIGURE 7 | (A) First discharge profile of the Ag-coated Cu/PLA/PEGDME500 sample versus sodium metal; (B) capacity retention plot for the HC powder deposited on top of the 3D printed PLA/Ag-coated Cu/PEGDME500 current collector.

material/carbon black ratio and mixing process that still requires to be optimized.

Furthermore, the application of the Ag-coated Cu/PLA/ PEGDME500 sample as current collector within a sodiumbased battery technology was also considered. First, the 3D printed disc was tested vs. sodium metal. As depicted in Figure $7 \mathrm{~A}$ representing the first discharge profile of the $\mathrm{Ag}$ coated Cu/PLA/PEGDME500 sample vs. sodium metal, no plateau corresponding to the alloying process between $\mathrm{Ag}$ and $\mathrm{Na}$ metal was observed. In this context, from the electrochemical 
point of view, it appears that the $\mathrm{Ag}$-coated $\mathrm{Cu}$-based current collector developed in this work can be extensively employed on the negative electrode side for a wide range of active materials. This was indeed confirmed through testing a cell in which HC powder was deposited on top of the Ag-coated Cu/PLA/ PEGDME500 current collector sample. As shown in Figures 7A,B a reversible capacity of $269 \mathrm{mAhg}^{-1}$ of active material after ten cycles was exhibited.

While a polar polymer matrix (PLA) was introduced in this preliminary study, it must be replaced in the future by a nonpolar and inert matrix such as polyolefin (PP or PE). Indeed, as demonstrated in our previous study (Maurel et al., 2020b), PLA swells when soaked in the liquid electrolyte; thus, it is suspected to have a detrimental effect on electronic conductivity. While this behavior is particularly interesting for a separator, it will significantly limit the long-term mechanical performance of a current collector.

\section{CONCLUSION}

In this work, the development of an Ag-coated $\mathrm{Cu}$ polylactic acid (PLA) thermoplastic composite filament for its use, once 3D printed via TME, as current collector at the negative electrode side of a classical LIB or sodium-ion battery, has been demonstrated. The high electronic conductivity was achieved here through the deposition of $\mathrm{Ag}$ coating on top of $\mathrm{Cu}$ powder (after previous etching), while the filament mechanical performance was improved through the incorporation of poly(ethylene glycol) dimethyl ether average $M_{n} \sim 500$ (PEGDME500) as a plasticizer into the PLA polymer matrix. While printability of the resulting bespoke filament still remains complex due to its composite nature (up to 46 vol\% of charges), its electrical and electrochemical ability making it suitable for use

\section{REFERENCES}

Armand, M., Grugeon, S., Vezin, H., Laruelle, S., Ribière, P., Poizot, P., et al. (2009). Conjugated dicarboxylate anodes for Li-ion batteries. Nat. Mater. 8 (2), 120-125. doi:10.1038/nmat2372

Browne, M. P., Redondo, E., and Pumera, M. (2020). 3D printing for electrochemical energy applications. Chem. Rev. 120 (5), 2783-2810. doi:10. 1021/acs.chemrev.9b00783

Cheng, M., Deivanayagam, R., and Shahbazian-Yassar, R. (2020). 3D printing of electrochemical energy storage devices: a review of printing techniques and electrode/electrolyte architectures. Batteries \& Supercaps 3 (2). 130-146. doi:10. 1002/batt.201900130

Cohen, E., Menkin, S., Lifshits, M., Kamir, Y., Gladkich, A., Kosa, G., et al. (2018). Novel rechargeable 3D-Microbatteries on 3D-printed-polymer substrates: feasibility study. Electrochimica Acta 265, 690-701. doi:10.1016/j.electacta. 2018.01.197

Costa, C. M., Gonçalves, R., and Lanceros-Méndez, S. (2020). Recent advances and future challenges in printed batteries. Energ. Storage Mater. 28, 216-234. doi:10. 1016/j.ensm.2020.03.012

Egorov, V., Gulzar, U., Zhang, Y., Breen, S., and O’Dwyer, C. (2020). Evolution of 3D printing methods and materials for electrochemical energy storage. $A d v$. Mater. 32 (29), 2000556. doi:10.1002/adma.202000556

Forestier, C., Grugeon, S., Davoisne, C., Lecocq, A., Marlair, G., Armand, M., et al. (2016). Graphite electrode thermal behavior and solid electrolyte interphase as current collector was established. Although the current collector developed in this work was shown to form an alloy with lithium metal at $0.08 \mathrm{~V}$, its use with active materials such as LTO or $\mathrm{Li}_{2} \mathrm{TP}$ depicting a plateau at higher potentials was confirmed. Finally, its wide use as current collector at the negative electrode side was verified. No alloy formation with sodium metal was observed, thus confirming its use with a wide range of active materials such as HC. This preliminary study, here, paves the way toward the future optimization (a compromise between electrochemical/electrical and mechanical/printability performance) of such LIB/SIB current collector filament for $3 \mathrm{D}$ printing application via TME.

\section{DATA AVAILABILITY STATEMENT}

The original contributions presented in the study are included in the article/Supplementary Material; further inquiries can be directed to the corresponding author

\section{AUTHOR CONTRIBUTIONS}

Each author contributed equally to the research and writing steps.

\section{ACKNOWLEDGMENTS}

This work was supported by the Fonds Européen de Développement Régional (FEDER), the Conseil Régional des Hauts-de-France, and the Université de Picardie Jules Verne (UPJV). The authors would like to thank M. Courty for technical assistance (DSC) and the UPJV microscopy platform for sharing their facilities.

investigations: role of state-of-the-art binders, carbonate additives and lithium bis(fluorosulfonyl)imide salt. J. Power Sourc. 330, 186-194. doi:10.1016/j. jpowsour.2016.09.005

Fu, K., Wang, Y., Yan, C., Yao, Y., Chen, Y., Dai, J., et al. (2016). Graphene oxidebased electrode inks for 3D-printed lithium-ion batteries. Adv. Mater. Weinheim 28 (13), 2587-2594. doi:10.1002/adma.201505391

Grugeon, S., Laruelle, S., Herrera-Urbina, R., Dupont, L., Poizot, P., and Tarascon, J.-M. (2001). Particle size effects on the electrochemical performance of copper oxides toward lithium. J. Electrochem. Soc. 148 (4), A285-A292. doi:10.1149/1.1353566

Gulzar, U., Glynn, C., and O’Dwyer, C. (2020). Additive manufacturing for energy storage: methods, designs and material selection for customizable $3 \mathrm{D}$ printed batteries and supercapacitors. Curr. Opin. Electrochemistry 20, 46-53. doi:10. 1016/j.coelec.2020.02.009

Hai, H. T., Ahn, J. G., Kim, D. J., Lee, J. R., Chung, H. S., and Kim, C. O. (2006). Developing process for coating copper particles with silver by electroless plating method. Surf. Coat. Technology 201 (6), 3788-3792. doi:10.1016/j.surfcoat.2006.03.025

Koto, N. Y., Yukawa, J., and Moro, T. (1987). Process for the production of a silver coated copper powder and conductive coating composition. US Patent Number $4,652,465$.

Lee, Y.-S., Yoon, J.-S., Jo, Y.-R., Lee, H., and Rha, S.-K. (2013). Dilute H2SO4 solution for copper seed cleaning in electroplating. Trans. Nonferrous Met. Soc. China 23 (2), 562-566. doi:10.1016/s1003-6326(13)62500-5

Li, F.-J., Zhang, S.-D., Liang, J.-Z., and Wang, J.-Z. (2015). Effect of polyethylene glycol on the crystallization and impact properties of polylactide-based blends. Polym. Adv. Technol. 26 (5), 465-475. doi:10.1002/pat.3475 
Long, J. W., Dunn, B., Rolison, D. R., and White, H. S. (2004). Three-dimensional battery architectures. Chem. Rev. 104 (10), 4463-4492. doi:10.1021/cr0207401

Long, J. W., Dunn, B., Rolison, D. R., and White, H. S. (2020). 3D architectures for batteries and electrodes. Adv. Energ. Mater. 10 (46), 2002457. doi:10.1002/ aenm.202002457

Lyu, Z., Lim, G. J. H., Koh, J. J., Li, Y., Ma, Y., Ding, J., et al. (2020). Design and manufacture of 3D-printed batteries. Joule 5, 89-114. doi:10.1016/j.joule.2020.11.010

Maurel, A., Courty, M., Fleutot, B., Tortajada, H., Prashantha, K., Armand, M., et al. (2018). Highly loaded graphite-polylactic acid composite-based filaments for lithium-ion battery three-dimensional printing. Chem. Mater. 30 (21), 7484-7493. doi:10.1021/acs.chemmater.8b02062

Maurel, A., Grugeon, S., Fleutot, B., Courty, M., Prashantha, K., Tortajada, H., et al. (2019). Three-dimensional printing of a LiFePO4/graphite battery cell via fused deposition modeling. Sci. Rep. 9 (1), 18031. doi:10.1038/s41598-019-54518-y

Maurel, A. (2020). Thermoplastic composite filaments formulation and 3Dprinting of a lithium-ion battery via fused deposition modeling. PhD Thesis. Amiens, (France): Université de Picardie Jules Verne.

Maurel, A., Armand, M., Grugeon, S., Fleutot, B., Davoisne, C., Tortajada, H., et al. (2020a). Poly(Ethylene oxide)-LiTFSI solid polymer electrolyte filaments for fused deposition modeling three-dimensional printing. J. Electrochem. Soc. 167 (7), 38. doi:10.1149/1945-7111/ab7c38

Maurel, A., Haukka, M., MacDonald, E., Kivijärvi, L., Lahtinen, E., Kim, H., et al. (2020b). Considering lithium-ion battery 3D-printing via thermoplastic material extrusion and polymer powder bed fusion. Additive Manufacturing 37, 101651. doi:10.1016/j.addma.2020.101651

Maurel, A., Grugeon, S., Armand, M., Fleutot, B., Courty, M., Prashantha, K., et al. (2020c). Overview on lithium-ion battery 3D-printing by means of material extrusion. ECS Trans. 98 (13), 3-21. doi:10.1149/09813.0003ecst

Myung, S.-T., Hitoshi, Y., and Sun, Y.-K. (2011). Electrochemical behavior and passivation of current collectors in lithium-ion batteries. J. Mater. Chem. 21 (27), 9891-9911. doi:10.1039/c0jm04353b

Pang, Y., Cao, Y., Chu, Y., Liu, M., Snyder, K., MacKenzie, D., et al. (2019). Additive manufacturing of batteries. Adv. Funct. Mater. 30, 1906244. doi:10.1002/adfm. 201906244

Ragones, H., Menkin, S., Kamir, Y., Gladkikh, A., Mukra, T., Kosa, G., et al. (2018). Towards smart free form-factor 3D printable batteries. Sustainable Energ. Fuels 2 (7), 1542-1549. doi:10.1039/c8se00122g

Ragones, H., Vinegrad, A., Ardel, G., Goor, M., Kamir, Y., Dorfman, M. M., et al. (2019). On the road to a multi-coaxial-cable battery: development of a novel 3D-printed composite solid electrolyte. J. Electrochem. Soc. 167 (1), 070503. doi:10.1149/2.0032007jes
Reyes, C., Somogyi, R., Niu, S., Cruz, M. A., Yang, F., Catenacci, M. J., et al. (2018). Three-dimensional printing of a complete lithium ion battery with fused filament fabrication. ACS Appl. Energ. Mater. 1 (10), 5268-5279. doi:10. 1021/acsaem.8b00885

Singh, N., Galande, C., Miranda, A., Mathkar, A., Gao, W., Reddy, A. L., et al. (2012). Paintable battery. Sci. Rep. 2, 481. doi:10.1038/srep00481

Sun, K., Wei, T. S., Ahn, B. Y., Seo, J. Y., Dillon, S. J., and Lewis, J. A. (2013). 3D printing of interdigitated Li-ion microbattery architectures. Adv. Mater. Weinheim 25 (33), 4539-4543. doi:10.1002/adma.201301036

Taberna, P. L., Mitra, S., Poizot, P., Simon, P., and Tarascon, J. M. (2006). High rate capabilities $\mathrm{Fe} 3 \mathrm{O} 4$-based $\mathrm{Cu}$ nano-architectured electrodes for lithium-ion battery applications. Nat. Mater. 5 (7), 567-573. doi:10.1038/nmat1672

Trembacki, B., Duoss, E., Oxberry, G., Stadermann, M., and Murthy, J. (2019). Mesoscale electrochemical performance simulation of 3D interpenetrating lithium-ion battery electrodes. J. Electrochem. Soc. 166 (6), A923-A934. doi:10.1149/2.0031906jes

Yang, P. H., and Fan, H. J. (2020). Inkjet and extrusion printing for electrochemical energy storage: a minireview. Adv. Mater. Tech. 5 (10), 11. doi:10.1002/admt. 202000217

Yang, Y., Yuan, W., Zhang, X., Yuan, Y., Wang, C., Ye, Y., et al. (2020). Overview on the applications of three-dimensional printing for rechargeable lithium-ion batteries. Appl. Energ. 257, 114002. doi:10. 1016/j.apenergy.2019.114002

Zeng, L., Li, P., Yao, Y., Niu, B., Niu, S., and Xu, B. (2020). Recent progresses of 3D printing technologies for structural energy storage devices. Mater. Today Nano 12, 13. doi:10.1016/j.mtnano.2020.100094

Zhang, M., Mei, H., Chang, P., and Cheng, L. (2020). 3D printing of structured electrodes for rechargeable batteries. J. Mater. Chem. A. 8 (21), 10670-10694. doi:10.1039/d0ta02099k

Conflict of Interest: The authors declare that the research was conducted in the absence of any commercial or financial relationships that could be construed as a potential conflict of interest.

Copyright (c) 2021 Maurel, Kim, Russo, Grugeon, Armand, Panier and Dupont. This is an open-access article distributed under the terms of the Creative Commons Attribution License (CC BY). The use, distribution or reproduction in other forums is permitted, provided the original author(s) and the copyright owner(s) are credited and that the original publication in this journal is cited, in accordance with accepted academic practice. No use, distribution or reproduction is permitted which does not comply with these terms. 